\title{
DESENVOLVIMENTO RURAL: AFINAL, SOBRE O QUE ESTAMOS FALANDO?
}

\section{RURAL DEVELOPMENT: WHAT ARE WE TALKING ABOUT?}

\author{
Daniela Dias Kühn \\ Universidade Federal de Santa Maria - Santa Maria - RS - Brasil
}

\begin{abstract}
Resumo: A expressão desenvolvimento vem sendo cada vez mais utilizada e está consolidada no estudo das realidades socioeconômicas. Entretanto, há, ainda, de se limitar o alcance da expressão, bem como a qualificação. O presente artigo discute o significado da expressão desenvolvimento rural, reunindo autores e buscando tematizar sobre os conceitos envolvidos na expressão. $O$ objetivo principal deste trabalho é, a partir de uma revisão bibliográfica do conceito de desenvolvimento rural e de uma contextualização da Abordagem das Capacitações, indicar como a referida abordagem pode contribuir para a construção de um conceito de desenvolvimento rural mais adequado à diversidade inerente ao ambiente em análise. Para isso, foi realizada uma breve revisão daquilo que vem sendo discutido sobre processos de desenvolvimento e como esse processo se associa à expressão rural. O termo desenvolvimento é analisado a partir da construção de suas interpretações no processo de conceituação e desenvolvimento teórico. Foi possível reconhecer os principais adjetivos, bem como a evolução dessas discussões nos últimos 30 anos. Por fim, é identificado um conceito associado à Abordagem das Capacitações, apresentado pelo economista indiano Amartya Sen. A ideia de desenvolvimento rural, associada à Abordagem das Capacitações, leva a uma concepção que identifica o desenvolvimento rural como um aumento da possibilidade de escolha dos indivíduos que residem em ambientes constituídos por relações socioeconômicas, geográficas e culturais que evidenciam, por meio da paisagem, a utilização e (ou) preservação de aspectos relacionados à Natureza cuja reprodução não é inteiramente dependente e (ou) condicionada pela ação humana.
\end{abstract}

Palavras-chave: Desenvolvimento rural. Abordagem das Capacitações.

Abstract: The development expression has been increasingly used and consolidated in the study of socioeconomic realities. However, there is still to limit the scope of the term as well as qualification. This article discusses the significance of rural development expression, bringing together authors and seeking foregrounding of the concepts involved in the expression. The main objective of this work is, from a literature review of the concept of rural development and a context of the Capability Approach, indicate how this approach can contribute to the construction of a rural development concept better suited to the diversity inherent in the environment under review. For this, a brief review was made of what has been discussed about the development process and how this process is associated with rural expression. The term development is analyzed from the construction of their interpretations of concepts and theoretical development. It was possible to recognize the main adjectives, as well as the evolution of these discussions over the last 30 years. Finally, it identified a concept associated with the Capability Approach, presented by the Indian economist Amartya Sen. The idea of rural development associated with the Capability Approach, leads to a design that identifies rural development as an increase in choice of individuals residing in environments made up of socio-economic, geographical and cultural relations that show through the landscape, use and (or) preservation of aspects related to nature whose reproduction is not entirely dependent and (or) conditioned by human action.

Keywords: Rural development. Capability Approach. 


\section{INTRODUÇÃO}

Desde que a expressão "desenvolvimento" ganhou os mais diversos adjetivos, é difícil estabelecer exatamente o significado de expressões que surgem como capazes de qualificar de forma definitiva os mais variados discursos políticos. Este breve ensaio ocupa-se em discutir algumas características do processo social que vem sendo designado como "desenvolvimento rural".

Considerando a existência de uma preocupação em incentivar processos de desenvolvimento (de uma maneira muito geral, compreendido como um processo de melhoria das condições de vida das pessoas e por esse motivo aceito como "uma coisa boa") é tempo de consolidar o conteúdo da expressão reconhecida como desenvolvimento rural. Nesse sentido, o objetivo principal deste trabalho é, a partir de uma revisão bibliográfica e de uma contextualização da Abordagem das Capacitações, indicar como a referida abordagem pode contribuir para a construção de um conceito de desenvolvimento rural mais adequado à diversidade inerente do ambiente em análise. Para isso é realizada uma breve revisão daquilo que vem sendo discutido sobre processos de desenvolvimento e como esse processo se associa à expressão rural. Por fim, a tentativa é a de propor, ainda de maneira incipiente, um conceito restrito a essa noção capaz de ser permeado pela diversidade presente no ambiente reconhecido contemporaneamente como rural.

O trabalho apresenta um conjunto de conceitos de desenvolvimento, um conjunto de elementos identificados como rural, bem como a evolução do debate e do conceito de desenvolvimento rural para, por fim, apresentar uma nova sugestão de conceituação que envolva esses dois temas. Foram organizados, a partir de uma revisão bibliográfica, alguns dos conceitos mais utilizados neste debate.

Certamente, o objetivo aqui não é esgotar uma discussão como esta, o que ocuparia muito mais páginas do que aquelas que um artigo como este dispõe. Trata-se aqui de evidenciar uma questão que, por algum tempo, causou-me certa inquietação pessoal, por que estudar desenvolvimento rural? Existe algo que poderia ser caracterizado como desenvolvimento rural? Por que não estudar simplesmente desenvolvimento - sem qualquer adjetivo? Ainda que todas essas perguntas não estejam aqui respondidas, espera-se apenas ratificar que é possível, sim, identificar, a partir de características definidas, um processo que pode ser chamado de desenvolvimento rural. Essas características estão ligadas a aspectos de paisagem, à relação Homem-Natureza e, em termos socioeconômicos, à racionalidade da unidade de consumo/produção que habita o espaço rural. Ou seja, em tempos de globalização, é preciso compreender em que medida as relações sociais locais rurais estão se transformando e possibilitando a melhoria da qualidade de vida dessas populações. A preocupação aqui não é a de retomar a noção idílica do "campo", mas discutir como a dialética global/local que caracteriza essa nova "reestruturação rural" - para usar a expressão de Marsden (1990).

Para isso, este artigo está dividido em quatro seções, além desta introdução e das considerações finais. A primeira seção dedica-se a discutir como a expressão 
desenvolvimento passou a fazer parte da discussão sobre processos sociais, essencialmente a distinção entre crescimento econômico e desenvolvimento. Em seguida, discutem-se os diversos adjetivos associados à palavra desenvolvimento e, na medida do possível, suas diferenças e semelhanças. A terceira seção apresenta a noção de rural e as transformações em relação à discussão sobre ruralidade. Por fim, identifica-se a noção de desenvolvimento rural em si, procurando caracterizála a partir de alguns aspectos constituídos com enfoque nas diferenças entre meios e fins, nas possibilidades do agente e nas relações sociais características do meio rural - associadas à Abordagem das Capacitações, sugerida pelo economista Amartya Sen.

\section{DESENVOLVIMENTO: UMA NOÇÃO ALÉM DO CRESCIMENTO ECONÔMICO}

Ainda hoje, diversos estudiosos, especialmente economistas, não abandonaram a ideia de que crescimento econômico é sinônimo de um processo social que possa ser chamado de desenvolvimento.

Convém, muito brevemente, retomar como essas noções foram historicamente constituídas. Desde o período anterior ao processo de produção capitalista, a possibilidade de aumentos da produção de mercadorias tem representado um aumento na possibilidade de trocas e, por isso, uma possibilidade da melhoria da qualidade de vida dos produtores daquela mercadoria (já que isso, grosso modo, significa invariavelmente o acesso a outros bens e mercadorias). Pois bem, essa noção primitiva de aumento da produção, transformado em crescimento econômico, que supria minimamente a explicação das economias mercantis (com uma quantidade de bens infinitamente menor do que aquelas que o sistema de produção capitalista nos oferece atualmente) não pode mais ser utilizada como sinônimo de desenvolvimento impunemente.

Se, durante algum tempo, crescimento e desenvolvimento foram utilizados como sinônimos na literatura econômica, essa relação não é mais tão direta em termos de realidade social. O crescimento econômico refere-se basicamente a aumentos de produtividade. Ou seja, está diretamente ligado a mudanças na clássica relação capital-trabalho. O crescimento econômico está relacionado a um aumento na eficiência da utilização dos fatores de produção, o que significa uma das duas hipóteses: ou se produz mais com a mesma quantidade de fatores, ou se produz a mesma quantidade economizando os fatores de produção mais escassos (que são, por hipótese da teoria, aqueles mais caros). Esse raciocínio está fortemente associado à adoção das novas tecnologias (nas primeiras décadas do século $X X$ ) que representaram, além de novos produtos, um barateamento nos custos de produção, um mercado de massa e um significativo aumento do emprego assalariado nos núcleos urbanos (SEN, 2000). Além disso, o período histórico que consolidou essa noção de desenvolvimento como crescimento foi a solução encontrada para a Grande Depressão do século passado (1929). Ainda que o próprio Adam Smith ("pai" da Ciência Econômica e da economia dita liberal) identificasse claramente alguns aspectos socialmente negativos da Revolução Industrial - portanto, dos aumentos de produtividade e do crescimento econômico 
-, foi o gasto estatal para a recuperação da sociedade norte-americana por meio do crescimento do produto interno desse país que consolidou a ideia de que crescimento econômico pode ser naturalmente associado a um processo de desenvolvimento. Os próprios índices de crescimento e diversos modelos macroeconômicos, que ainda hoje são utilizados como instrumentos de desenvolvimento dos países, foram desenvolvidos - em sua ideia geral - pelo próprio Keynes neste período.

Ao sair de tamanha crise econômica, como a que abalou o mundo no início da década de 1930, o crescimento econômico acabou por refletir uma melhoria da qualidade de vida das pessoas. Sem considerar a questão ambiental, que apenas desde a década de 1980 é discutida, o crescimento econômico foi responsável por desenvolvimento naquele contexto. Entretanto, o processo de globalização, já discutido em muitos outros trabalhos ${ }^{1}$, gerou uma sociedade cada vez mais desigual e que não pode ter, dada a grande diversidade de situações sociais, um único exemplo a seguir. Salientando que o objetivo deste trabalho não é o de aprofundar a discussão sobre globalização, nem apontar aspectos positivos e negativos deste processo, pode-se perceber que a integração econômicofinanceira possibilitada pelas tecnologias de informação permitiram que fluxos financeiros adquirissem uma lógica própria de flutuação entre os países. Essa noção é importante porque faz com que um determinado grupo de países tenha reduzido sua autonomia em relação à realização de política monetária ${ }^{2}$. $\mathrm{Na}$ tentativa de resumir superficialmente a complexidade desse processo, pode-se dizer que o processo de endividamento dos países (especialmente dos países periféricos) limita a possibilidade de gasto público para a promoção de políticas capazes de gerar processos reconhecidos como de crescimento econômico. Se a política econômica está voltada para o pagamento das dívidas, atreladas cada vez mais a uma política monetária restritiva, não há porque imaginar que o crescimento seja capaz de gerar, como consequência inequívoca, uma melhoria da qualidade de vida da população em geral.

É claro que não se trata aqui de negar completamente a importância do crescimento econômico para o desenvolvimento dos países, entretanto, é preciso compreender que esse crescimento deve estar associado a outros fatores, como a redução das desigualdades. O crescimento econômico pode ser fortemente incentivado como o instrumento de geração de superávits econômicos, mas não necessariamente um instrumento para acabar, por exemplo, com a fome (já que o problema da fome no mundo - e em muitos países, como o Brasil, não é o de produzir alimentos e, sim, de fazer com que as pessoas tenham acesso a essa mercadoria).

\footnotetext{
1 Por exemplo: HIRST, Paul, THOMPSON, Grahame. Globalização em questão. Petrópolis: Ed. Vozes. 1998.; DUPAS, Gilberto. Economia global e exclusão social: pobreza, emprego, estado e o futuro do capitalismo. São Paulo: Paz e Terra, 1999.

${ }^{2}$ De novo, alerta-se sobre a brevidade com que este assunto está sendo tratado aqui. As obras citadas na nota anterior, e muitas outras que tratam especificamente sobre a globalização, trazem aspectos não tão superficiais. Dados os objetivos do trabalho, o de discutir desenvolvimento rural, é que se opta neste momento por não aprofundar a discussão específica sobre o processo de globalização.
} 
Nesse sentido, a distinção que se pretende é a seguinte: se em alguns países o crescimento pode ser um instrumento que melhore a qualidade de vida das pessoas, em países sem essas condições estruturais, os instrumentos para a promoção do desenvolvimento podem ser outros. Se analisarmos a situação do Brasil, perceberemos que apesar de obtermos bons índices de crescimento econômico (quando comparados aos demais países) a desigualdade entre as pessoas diminui num ritmo bastante mais lento do que aquele do crescimento. Yunus (2000, p. 266), preocupado em compreender e desenvolver instrumentos para redução da pobreza em Bangladesh, indica que:

\begin{abstract}
é nesse ponto que crescimento e desenvolvimento se separam. Aqueles que consideram que essas duas palavras são sinônimas ou estão intrinsecamente ligadas acham que as camadas sociais se atrelam umas as outras como os vagões de um trem de ferro. Tudo que é necessário é a locomotiva se mover, assim todos os vagões a seguem na mesma velocidade. Nem de longe é esse o caso. Além de as diferentes camadas não progredirem na mesma velocidade, se não formos cuidadosos elas não tomarão a mesma direção.
\end{abstract}

Ainda que se tenha tentado demonstrar a inadequação de considerar como sinônimos as expressões crescimento econômico e desenvolvimento, este trabalho não é inovador em constatar essa realidade. Cada vez mais cientistas e formuladores de políticas públicas têm chamado a atenção para a necessidade de tratar separadamente os dois processos sociais.

Mas, se há necessidade de distinção entre as duas expressões, então, o que é desenvolvimento? Para essa questão há uma infinidade de respostas e é esse o assunto apresentado na próxima seção.

\title{
3 DESENVOLVIMENTO E DESENVOLVIMENTO RURAL: A EVOLUÇÃO DOS CONCEITOS
}

Talvez essa seja uma das perguntas que os cientistas sociais tenham maior dificuldade em responder. Se estivermos de acordo que o crescimento não gera, necessariamente, desenvolvimento, é preciso saber o que é desenvolvimento e o que, então, é preciso para incentivar esses processos nas comunidades mais carentes de diversos recursos. Há certa noção de que desenvolvimento representa uma melhoria da qualidade de vida da maioria das pessoas que vivem nas piores condições de determinadas regiões.

A percepção de que o desenvolvimento vai além do crescimento econômico, talvez aliado ao fato de que durante muito tempo as duas expressões tenham sido confundidas, fez com que vários pesquisadores adjetivassem esse substantivo na busca da definitiva distinção entre os dois processos sociais.

Uma das expressões mais difundidas atualmente é a de desenvolvimento sustentável. Ela é uma das mais conhecidas porque foi "criada" pela Organização das Nações Unidas (ONU) numa tentativa de tentar incorporar, essencialmente, 
fatores ambientais na análise do processo de desenvolvimento. A inclusão desse aspecto foi uma tentativa de amenizar a pressão contra um processo de crescimento econômico que utiliza a Natureza como recurso - os ditos "recursos naturais" - e não está necessariamente preocupada em perceber que tipo de dano ambiental - reversível ou não - esse processo tem feito. Ainda que incorpore a importante questão ambiental como um aspecto que necessita de atenção, o discurso oficial do desenvolvimento sustentável está intimamente associado à noção do crescimento econômico e do progresso. Ou seja, para a ONU, o processo de desenvolvimento sustentável é sustentável ao longo do tempo. O objetivo é que as gerações futuras tenham condições de desfrutar das condições de progresso que nós desfrutamos hoje (CMMAD, 1991). Entretanto, o que será esse progresso? Mais uma vez, essa noção, por estar associada ao crescimento, não consegue dar conta da diversidade das situações encontradas no planeta e sugere uma "receita" de relação com o meio ambiente (que é baseada naquela do desperdício e da desigualdade da sociedade ocidental). A restrição da noção de sustentabilidade do conceito da ONU à questão temporal retoma a crença de que, no futuro, a tecnologia será capaz de resolver parte significativa dos problemas gerados pelo crescimento econômico e, por isso, crescimento e desenvolvimento não precisam ser considerados processos distintos.

Essa noção de sustentabilidade é contestada em diversos aspectos. Alguns autores indicam que o desenvolvimento sustentáve/ é aquele que está relacionado à (im)possibilidade de expansão dos padrões de consumo atual a todos os habitantes do planeta. Dessa forma, pondera-se que o padrão de consumo dos países centrais não é sustentável, caso o objetivo político seja o de levá-lo a todas as pessoas. Se o modo de vida gerado pelo progresso pós Revolução Industrial (pelo crescimento econômico) fosse estendido a todas as pessoas, não haveria planeta nem recursos suficientes ${ }^{3}$. Existem, ainda, autores que indicam que essa expressão é uma contradição em si (talvez, novamente, pela confusão entre crescimento e desenvolvimento). $O$ argumento é o de que quando o meio ambiente é afetado pelo desenvolvimento, que tem como objetivo transformar a natureza em elemento a ser incorporado no processo de reprodução social, ele já não é mais sustentável (SACHS, 1997). Sem a intenção de alongar essa discussão, o importante é perceber que uma das noções mais difundida entre os pesquisadores e entre a comunidade em geral apresenta muitas controvérsias ${ }^{4}$.

A noção de desenvolvimento foi, também, associada à ideia de modificação das formas de relação entre o meio rural e a sociedade em geral. Caracterizando a análise dessa relação em diversos ambientes foi sugerida a expressão

\footnotetext{
${ }^{3}$ É o que nos apresentam diversos trabalhos como: FERNANDEZ, Xavier Simon. El análisis de sistemas agrarios: una aportación economico-ecológica a una realidad compleja. História Agraria. N 19, 1999.; MERICO, Luiz F.K. Introdução a Economia Ecológica. Blumenau: Editora da FURB, 1996.

${ }^{4}$ Uma frase interessante sobre o desenvolvimento é a seguinte: "O mundo pode ter se desenvolvido, mas em direções opostas" (SACHS, 1997; p.13). Que mundo? Que direção? Que desenvolvimento? No contexto do artigo, o autor referia-se ao espantoso aumento das desigualdades entre os países do Norte e do Sul do planeta: "Desde 1960, de acordo com o relatório do desenvolvimento Humano de 1996, a distância entre os países industrializados e os em desenvolvimento triplicou em termos de renda per capita" (SACHS, 1997; p.13).
} 
desenvolvimento agrário (NAVARRO, 2001). Esses estudos preocupam-se em perceber a transformação do meio rural, essencialmente a partir de uma perspectiva de inserção desses espaços na lógica capitalista de produção, destacando os processos sociais de transmissão e propriedade da terra, como fator essencial de produção. Há aqui um corte que vai além do econômico, já que o conceito procura incorporar uma reconstituição histórica. Esse tipo de análise apresenta ao leitor a construção das relações capitalistas de produção (agropecuária), bem como suas contradições no ambiente rural.

Ainda chamando a atenção para um mundo rural, a expressão desenvolvimento agrícola está ligada à atividade agrícola e suas condições materiais de produção (NAVARRO, 2001). Mais uma vez esse adjetivo que segue desenvolvimento está associado ao processo de crescimento econômico, ligado à difusão de técnicas na organização da produção de uma atividade econômica - a agropecuária. Essa expressão é referida quando é realizada a análise de cadeias agropecuárias e agroindústrias.

Assim como no caso do desenvolvimento agrícola, a expressão desenvolvimento industrial é comumente encontrada na literatura das Ciências Econômicas para designar um aumento na diversidade do tipo de indústrias e qualificação das relações econômicas entre as indústrias de determinado lugar. Há aqui um viés setorial em termos de produção, tanto num caso como no outro. Um recorte setorial específico. O debate em torno do processo de desenvolvimento industrial envolve distribuição espacial de empresas, análise do tamanho das empresas, bem como da sua estrutura de mercado, relação dessa produção com o comércio internacional (AGUIAR, 1991).

Com o debate político, inaugurado através da retirada do Estado da gestão das atividades produtivas, há uma crescente preocupação com o desenvolvimento local. A queda na capacidade de investimento público leva à discussão de um processo que envolve as possibilidades de aperfeiçoamento e incremento das relações sociais que são espacialmente próximas. O fortalecimento do desenvolvimento local é associado à melhoria da qualidade de vida dos moradores de áreas geograficamente determinadas (NAVARRO, 2001) incentivado, ou não, com recursos estatais.

Se a expressão desenvolvimento local poderia ser acusada de certa inviabilidade metodológica, já que cada lugar deve organizar-se a partir de suas especificidades, o conceito de desenvolvimento regional está associado exatamente ao planejamento ou à análise de resultados de determinada ação pública do Estado que abrange uma área geográfica relativamente extensa (considerando o "local"). Esse "desenvolvimento regional", muitas vezes, pela análise de variáveis agregadas não consegue perceber os fatores que efetivamente poderiam estar influenciando no aumento da qualidade de vida das pessoas ${ }^{5}$ (LOPES, 2001).

\footnotetext{
${ }^{5}$ Considere-se aqui, novamente, a brevidade com que essas expressões estão sendo tratadas. Há um debate bastante interessante, envolvendo especificamente o conceito de desenvolvimento regional e a possibilidade metodológica de compreensão dessas heterogeneidades que pode ser bastante útil aos interessados na realidade brasileira, por exemplo (LOPES, 2001).
} 
Outra expressão derivada da incorporação de aspectos geográficos, para a tentativa de análise dos processos sociais de reprodução é desenvolvimento territorial. Essa noção envolve aspectos importantes de geografia política, grosseiramente falando. Ela tem ocupado o espaço de crítica que incide sobre o desenvolvimento local e regional (LOPES, 2001). O desenvolvimento territorial ocupa-se em apresentar relações socioeconômicas e geográficas que possibilitam a melhoria da qualidade de vida das pessoas. Por meio dessa abordagem, é possível conhecer aspectos relacionados à noção de pertencimento dos agentes sociais a esse processo de desenvolvimento, bem como, procura evidenciar as relações assimétricas de forças políticas envolvidas. É percebida, a partir dessa noção, a heterogeneidade do espaço geográfico para a proposição de políticas de desenvolvimento. Ainda assim, a dificuldade básica para a aceitação desse conceito (que por si só já tem derivado um grande debate) refere-se à definição da unidade de análise para conceituar esse desenvolvimento - o território ${ }^{6}$.

Percebe-se, então, que a expressão desenvolvimento foi associada a diversas categorias de análise que possibilitam níveis diferentes de reflexão e de recorte de possíveis objetos de pesquisa. O quadro abaixo procura apresentar os conceitos associados à expressão desenvolvimento que foram retomados neste trabalho.

\section{Quadro 1. Dimensões do Desenvolvimento}

\begin{tabular}{|c|c|c|}
\hline Conceito Associado & Aspecto Positivo & Limite \\
\hline Econômico & $\begin{array}{l}\text { Bastante utilizado na literatura } \\
\text { econômica. }\end{array}$ & $\begin{array}{l}\text { Confunde-se com a noção de } \\
\text { crescimento. Essencialmente } \\
\text { quantitativo. }\end{array}$ \\
\hline Sustentável & $\begin{array}{l}\text { Incorpora a discussão em } \\
\text { relação ao meio ambiente. }\end{array}$ & $\begin{array}{l}\text { Está ainda muito associado à } \\
\text { noção de desenvolvimento } \\
\text { como crescimento. }\end{array}$ \\
\hline Agrário & $\begin{array}{l}\text { Estabelece bases de } \\
\text { comparação entre as diversas } \\
\text { situações do mundo rural. }\end{array}$ & Estuda macro relações sociais. \\
\hline Agrícola & $\begin{array}{l}\text { Analisa condições de } \\
\text { infraestrutura da produção } \\
\text { agrícola. }\end{array}$ & \multirow{2}{*}{$\begin{array}{l}\text { Ligado a uma atividade } \\
\text { econômica. }\end{array}$} \\
\hline Industrial & $\begin{array}{l}\text { Analisa condições de } \\
\text { infraestrutura da produção } \\
\text { industrial. }\end{array}$ & \\
\hline Local & $\begin{array}{l}\text { Ressalta importância das } \\
\text { estruturas locais. }\end{array}$ & $\begin{array}{l}\text { Associado ao discurso de } \\
\text { enfraquecimento do Estado. }\end{array}$ \\
\hline Regional & $\begin{array}{l}\text { Importante em termos de } \\
\text { planejamento da atuação do } \\
\text { Estado. }\end{array}$ & $\begin{array}{l}\text { Confunde situações } \\
\text { heterogêneas. }\end{array}$ \\
\hline Territorial & $\begin{array}{l}\text { Estabelece diversas relações em } \\
\text { campos disciplinares diferentes. }\end{array}$ & $\begin{array}{l}\text { Debate sobre a definição de } \\
\text { território. }\end{array}$ \\
\hline
\end{tabular}

Fonte: Elaborado pela autora.

\footnotetext{
${ }^{6}$ Utiliza-se aqui a noção de território identificada por Milton Santos (1994): "O território, hoje, pode ser formado de lugares contíguos e de lugares em rede: São, todavia, os mesmos lugares que formam redes e que formam o espaço banal. São os mesmos lugares, os mesmos pontos, mas contendo simultaneamente funcionalidades diferentes, quiçá divergentes ou opostas".
} 
Assim como as noções anteriormente especificadas, a palavra rural vem, desde 1950, sendo utilizada para identificar certa relação social, inicialmente associada, exclusivamente, à produção agrícola, que ocorre em um determinado ambiente. Ellis (2001), ao sugerir uma 'evolução dos 'temas' do desenvolvimento rural, indica que essa noção já esteve, ao longo do tempo, discutindo os seguintes aspectos centrais:

Anos 1950 - modernização, modelo de economias duais;

Anos 1960 - necessidade de transferência de tecnologia para aumentar a eficiência dos pequenos produtores;

Anos 1970 - abordagem das necessidades básicas, crescimento com redistribuição;

Anos 1980 - liberalização de mercados, alívio em situações de pobreza;

Anos 1990 - participação social, redução da pobreza;

Anos 2000 - descentralização, estratégias de sobrevivência, erradicação da pobreza.

Se, no quadro, a expressão desenvolvimento aparece envolvida em diversos contextos diferentes, aqui a noção de desenvolvimento rural vai, com o passar do tempo, metamorfoseando-se e sendo indicada por variáveis diferentes ao longo do tempo. Ainda que se deva chamar atenção para a necessidade e importância da contextualização histórica do processo de desenvolvimento, essa interpretação, mesmo que dedicada exclusivamente à análise do desenvolvimento rural, não responde à questão proposta neste trabalho: $O$ que é desenvolvimento rural? $\mathrm{A}$ evolução desse conceito, ao longo do século $X X$, de forma como foi apresentada, supõe certa homogeneidade do processo de desenvolvimento associado ao ambiente rural.

Nesse sentido, o processo de desenvolvimento rural estaria atualmente associado a processos de redução de pobreza rural que busquem, por meio das estratégias de sobrevivência, aumentar as oportunidades e o potencial dos pobres rurais (ELLIS, 2001). A ênfase dada às condições de pobreza rural está aparentemente associada ao discurso do Banco Mundial sobre desenvolvimento em geral, que vem apropriando-se da noção seniana de desenvolvimento, que na sequência do trabalho será discutida.

Outro autor que destaca a variação histórica da noção de processos sociais associados ao desenvolvimento rural é Navarro (2001). A resposta, entretanto, à nossa questão central aparece mais claramente definida quando o autor nos indica que: "Desenvolvimento Rural é entendido como uma ação previamente articulada que induz (ou pretende induzir) mudanças em um determinado ambiente social" (NAVARRO, 2002, p.3). Entretanto, essa noção de mudança, ainda que se admita que seja para uma melhoria da qualidade de vida para a maioria da população, está associada a uma visão passiva do agente social.

Saraceno (1995), ao utilizar a noção de desenvolvimento rural, sugere a substituição da noção de desenvolvimento rural pela de economias locais. A autora indica que o declínio das atividades agrícolas e as recentes tendências geradas a partir do processo de globalização (reversão dos processos migratórios e a 
possibilidade de uma difusão maior, difusão espacial das atividades econômicas) caracterizam esse processo de desenvolvimento associado ao meio rural.

A noção que vem sendo trazida de forma cada vez mais clara para a discussão do ambiente rural é aquela associada à identificação de características territoriais capazes de conformar um objeto de atuação na busca de um processo de desenvolvimento rural (VEIGA, s/d; SCHEJTMAN \& BERDEGUÉ, 2003). O debate, nesse campo, envolve o caminho a ser percorrido por esses territórios rurais. Alguns estudos caracterizam o território no sentido de perceber suas potencialidades para a inserção no mercado. Essa análise conduziria o debate para o âmbito produtivista, nem sempre o mais adequado, partindo de determinadas perspectivas, principalmente, se considerarmos relações ecológicas e ambientais. Certamente, a questão territorial significa um passo adiante na análise do desenvolvimento rural, mas não pode ser resumido por ela nem no enfoque exclusivo da geração renda.

Entre os fatores essenciais que devem ser incluídos no processo de Desenvolvimento Territorial Rural, Schejtman \& Berdegué (1993) indicam: 1) Condição necessária de sobrevivência das unidades produtivas - competitividade; 2) Inovação tecnológica; 3) Competitividade como fenômeno sistêmico; 4) Demanda externa como motor das transformações produtivas; 5) Essencialidade dos vínculos urbanos-rurais; 6) Desenvolvimento Territorial associado ao Desenvolvimento Institucional; e 7) Noção de território como uma construção social. O Quadro 2 apresenta a posição de alguns autores.

Quadro 2. Elementos associados ao debate sobre desenvolvimento rural

\begin{tabular}{|l|l|l|}
\hline \multicolumn{1}{|c|}{ Ideia associada } & Autor identificado & \multicolumn{1}{c|}{ Observações } \\
\hline $\begin{array}{l}\text { Metamorfoses históricas } \\
\text { do conceito de } \\
\text { desenvolvimento }\end{array}$ & Frank Ellis (2001) & $\begin{array}{l}\text { Propõem que atualmente o desenvolvimento } \\
\text { rural está associado a processos que devessem } \\
\text { apresentar estratégias de sobrevivência. }\end{array}$ \\
\hline $\begin{array}{l}\text { Avaliação do processo de } \\
\text { ação do Estado }\end{array}$ & $\begin{array}{l}\text { Zander Navarro } \\
\text { (2001) }\end{array}$ & $\begin{array}{l}\text { Associa desenvolvimento rural aos processos } \\
\text { de desenvolvimento agrícola, agrário, } \\
\text { sustentável e local. Desenvolvimento rural } \\
\text { como uma ação induzida pelo Estado para } \\
\text { modificar determinada realidade. }\end{array}$ \\
\hline Economias Locais & $\begin{array}{l}\text { Elena Saraceno é mais relevante falar sobre a dicotomia } \\
\text { (1995) }\end{array}$ & $\begin{array}{l}\text { rural-urbano. Desenvolvimento rural deveria } \\
\text { ser substituído pela noção de economias locais } \\
\text { - mudança em relação à noção de ruralidade. }\end{array}$ \\
\hline Territorial & $\begin{array}{l}\text { Júlio A. Berdegué } \\
\text { \& Alexander } \\
\text { Schejtman (2003), } \\
\text { José Eli da Veiga. }\end{array}$ & $\begin{array}{l}\text { Análise voltada à identificação de } \\
\text { heterogeneidades espaciais, que buscam a } \\
\text { identificação social. Há preocupação com a } \\
\text { difusão e desenvolvimento de tecnologias } \\
\text { produtivas adequadas ao ambiente local. }\end{array}$ \\
\hline
\end{tabular}

Fonte: Elaborado pela autora.

Os conceitos discutidos até então ainda não são capazes de esgotar todos os aspectos envolvidos na discussão, mas apresentam a diversidade de aspectos que podem ser tratados sobre o tema. As especificidades do debate em torno da 
expressão "rural" serão discutidas na próxima seção, para que, em seguida, seja possível sugerir um conceito capaz de identificar novas relações sociais nesse ambiente de desenvolvimento.

\section{ALGUMAS PERCEPÇÕES SOBRE O RURAL}

A sociedade moderna - caracterizada pelas mais diversas dicotomias - nos levou a uma situação em que a noção de urbano e rural é facilmente observável. Numa sequência de fotografias, por exemplo, qualquer pessoa facilmente diferencia o urbano do rural. Entretanto, quando há necessidade de responder por meio de conceitos mais elaborados, poucas pessoas concordariam em caracterizar teoricamente os ambientes fotografados.

Em poucas palavras, talvez seja possível salientar alguns aspectos sobre a construção dessa noção do rural que temos hoje. Ela foi construída como aquela que não era urbana. Isso ocorre devido à necessidade de aglomeração de pessoas para a produção capitalista que, com base em avanços tecnológicos, pode produzir cada vez mais tipos de mercadorias e mercadorias cada vez mais baratas para aqueles com acesso a recurso monetário, em termos de preços. Essa abundância de produtos e a possibilidade do assalariamento levaram à formação de núcleos urbanos que, ao longo do tempo, foram sendo dotados de infraestrutura para abrigar essas pessoas e famílias (os assalariados com possibilidade de trocar dinheiro por esses serviços). Nesse sentido, a "cidade", o núcleo urbano passou a ser identificado como o lugar próprio do progresso, onde era possível encontrar tudo e todos. O rural era a outra parte, muitas vezes foi associado a um "espaço vazio" (SARACENO, 1996).

Essa noção gerou uma interpretação dualista entre as relações rural e urbano. O rural, o espaço vazio, era responsável por esvaziar-se de pessoas, mandando a mão de obra para o meio urbano, para um maior "progresso". Além disso, esse espaço, cada vez mais "vazio", deveria ocupar-se em produzir aquilo que o meio urbano não conseguia, seja por falta de espaço, ou por falta de possibilidade de transformar em processos industriais, alimentos e matérias-primas para a indústria. Essa noção associou fortemente o ambiente rural àquele fora da cidade, àquele da atividade agrícola.

Já na década de 1980, com todas as políticas liberalizantes e com os problemas comerciais que atingiram os produtos agrícolas, especialmente a geração de grandes excedentes, foi preciso analisar novamente a noção do rural. Essa é uma discussão surgida na Europa por conta dos subsídios, dados aos produtores do meio rural, para a produção agrícola e para o cumprimento de "outras funções" sociais. Dessa forma, a discussão sobre ruralidade passa a incorporar aspectos além do agrícola como, por exemplo, preservação de paisagem, preservação de traços culturais e a geração de empregos não agrícolas.

A importação desse debate europeu se dá, não exclusivamente, mas de forma significativa, com o anunciado "novo rural brasileiro" de Graziano da Silva (1999). Esse autor procurou desenvolver um método de análise do rural na tentativa de identificar características das transformações ocorridas no Brasil. Entretanto, além de usar definição de rural do Instituto Brasileiro de Geografia e 
Estatística-IBGE, os estudos parecem não ter sido capazes de revelar um rural assim tão novo. Esse rural continua fortemente associado à produção agrícola e as mudanças percebidas demonstraram, muitas vezes, empregos não agrícolas precários, sem definir exatamente em que medida a atuação de políticas públicas deveria atuar na promoção desse novo rural. Além disso, enfatiza em grande medida a geração de renda como o instrumento principal para o rural.

Além da identificação de novas atividades sociais, o ambiente rural tem sido percebido pelos órgãos financeiros internacionais como o lugar da pobreza. $O$ corte do rural, como o que não é urbano, e da pobreza pela renda mostra que a pobreza é sempre proporcionalmente - em relação ao total da população - maior no meio rural. De um lugar "vazio" ou "esvaziado" a ideia de rural passa agora a ser associada a um lugar de pobres. A tabela a seguir identifica, com dados do Banco Mundial (2004), o percentual de pobres vivendo em regiões "urbanas" e em "rurais", a partir de indicadores selecionados de países selecionados.

Tabela 1. Indicador de Pobreza

\begin{tabular}{l|c|c|c}
\hline \multirow{2}{*}{ Localização } & \multicolumn{3}{|c}{$\begin{array}{r}\text { Linha de pobreza Nacional - \% da população } \\
\text { abaixo da linha de pobreza }\end{array}$} \\
\cline { 2 - 4 } & Rural & Urbano & Nacional \\
\hline África & 46,31 & 31,46 & 41,21 \\
\hline América Latina & 55,84 & 30,45 & 39,21 \\
\hline Ásia & 34,06 & 22,12 & 30,41 \\
\hline Europa Consolidada & 28,75 & 20,40 & 21,95 \\
\hline Nova Europa & 14,83 & 10,90 & 27,12 \\
\hline Oceania & 50,70 & 21,50 & 31,95 \\
\hline
\end{tabular}

Fonte: World Bank (2004).

Apesar das críticas que podem ser feitas com relação à construção de um indicador de pobreza baseado em renda e de um rural que não é urbano, a percepção de que há uma associação entre meio rural e condições de pobreza, pode levar a uma primeira ideia de que, se estamos preocupados em estudar processos capazes de melhorar a qualidade de vida das pessoas, talvez se deva passar por um estudo do rural.

Abramovay (2000), após um interessante trabalho em que faz uma retomada das diversas tentativas de dar um conceito ao rural, indica que:

a ruralidade não é uma etapa do desenvolvimento social a ser superada com o avanço do progresso e da urbanização. Ela é e será cada vez mais um valor para as sociedades contemporâneas. É em torno deste valor e não somente de suas atividades econômicas setoriais - que se procuraram aqui as características mais gerais do meio rural: relação com a natureza, regiões não-densamente povoadas e inserção em dinâmicas urbanas. A importância entre nós da agricultura não deve impedir uma definição territorial do desenvolvimento e do meio rural" (ABRAMOVAY, 2000. p.26). 
É dessa noção que, conforme se verá na próxima seção, aproxima-se a percepção do rural no contexto deste trabalho. Por fim, é preciso evidenciar que, em muitos estudos, a noção do rural está associada a um espaço físico e à existência de algum tipo de produção alimentar. Existem, ainda, alguns autores que procuram associar a noção do rural a uma categoria social realizada e não a um ambiente físico específico (CARNEIRO, 2001). Partindo de uma perspectiva sociológica associada à teoria bourdiana, a autora procura identificar elementos simbólicos que, nas práticas sociais dos agentes, estariam associados a uma imagem socialmente construída associada ao rural. Dessa forma, destituindo o rural e a ruralidade de seu espaço físico de apresentação e, num certo sentido, não viabilizando a análise de um processo de desenvolvimento que possa ser constituído como algo além da observação individual.

\section{DESENVOLVIMENTO RURAL: UMA TENTATIVA DE CONCEITO A PARTIR DA ABORDAGEM DAS CAPACITAÇÕES}

A indefinição em torno da noção de desenvolvimento rural indica, conforme já foi destacado, que há a possibilidade de inserção de novos aspectos que permitam a compressão de dinâmicas sociais que não podem ser simplificados ou transformados em agregados e estatística descritiva.

$\mathrm{Na}$ tentativa de estabelecer uma condição normativa para a análise do processo de desenvolvimento, Amartya Sen desenvolveu a Abordagem das Capacitações. Segundo essa noção, o processo de desenvolvimento, admitido como uma melhoria da qualidade de vida das pessoas, só pode ser reconhecido a partir da identificação de um aumento nas oportunidades a que estão submetidos os agentes sociais (SEN, 2000).

Para compreendermos os processos sociais, é preciso, em primeiro lugar, distinguir claramente o que pode ser considerado como um meio e um fim em relação ao processo de desenvolvimento. Conforme o autor, essa indeterminação está associada à confusão entre prosperidade econômica e desenvolvimento:

há, portanto, duas questões diferentes aqui. Primeiro: a prosperidade
econômica é apenas um dos meios para enriquecer a vida das pessoas. É
uma confusão no plano dos princípios, atribuir a ela o estatuto de
objetivo a alcançar. Segunda: mesmo como um meio, o mero aumento
da riqueza econômica pode ser ineficaz na consecução de fins realmente
valiosos. Para evitar que o planejamento do desenvolvimento e o
processo de formulação de políticas em geral sejam afetados por
custosas confusões de fins e meios, teremos de enfrentar a questão da
identificação dos fins, nos termos dos quais a eficácia dos meios possa
ser sistematicamente avaliada" (SEN, 1993.p.315).

O conceito fundamental da abordagem das capacitações é o de funcionamentos. Esse conceito está associado a atividades/ações (por exemplo, comer, ler, escrever) ou com estados de existência/estados (por exemplo, estar bem nutrido, não estar exposto a doenças) (SEN, 2001). O conjunto de funcionamentos disponíveis a uma determinada pessoa forma seu conjunto capacitário. Esse conjunto de possibilidade de escolhas reflete aquilo que está disponível ao agente em termos de oportunidades. Entre essas possibilidades de 
escolha devem estar presentes aqueles elementos que são valorizados pelo agente social para que seja levado aquilo que ele considera uma boa vida. Esse conceito está associado, então, às oportunidades de realização dos funcionamentos, se o conjunto capacitário aumenta, o processo de desenvolvimento pode ser caracterizado. Já que a pessoa, tendo mais uma opção, teria mais liberdade. Nesse sentido, e não em qualquer outro que se possa dar a essa palavra, é que Sen desenvolve a noção de "desenvolvimento como liberdade" (SEN, 2000). É importante ressaltar que uma discussão sobre a noção de justiça envolve a possibilidade de ordenamento daquilo que se poderia chamar de funcionamentos básicos ou primários.

A grande questão sociológica que afligiu e aflige muitos pesquisadores sociais entre ação e estrutura aparece nessa discussão como desenvolvimento de expansão de capacitações. Na questão da análise da pobreza, por exemplo, essa inquietação poderia ser traduzida da seguinte forma: o papel do pesquisador é o de demonstrar como esse problema ocorre e por que, estruturalmente, ele vem se reproduzindo, condenando gerações inteiras a essa estrutura ou, a partir da percepção da expansão da oportunidade na participação social, por exemplo, determinar que mecanismos sociais, quando acessados pelos agentes sociais, permitem a resolução desse problema? Tanto uma percepção como a outra - da imobilidade e da possibilidade total de transformação - já se demonstraram demasiadamente ingênuas para explicar a dinâmica realidade social. Nesse sentido, no mesmo tempo em que a abordagem das capacitações exige do processo de desenvolvimento um aumento nas possibilidades de escolha dos agentes, ela nos apresenta uma noção relacionada às condições de realização das escolhas por determinados funcionamentos - os intitulamentos. Os intitulamentos são "estabelecidos pelos ordenamentos legal, político e econômico" (SEN, 2001. P. 235). Além disso, é preciso atentar aos valores sociais envolvidos, pois os intitulamentos e funcionamentos devem refletir opções e escolhas que cada agente social tem razão para valorizar.

A análise está associada, nesse caso, a, pelo menos, dois níveis de compreensão: as opções dadas aos indivíduos e as escolhas realizadas. Sen (1993) chama a atenção de que, incorporando essas etapas à análise, é possível incorporar as oportunidades sociais em termos de justiça, voltando a análise da reprodução social capitalista para o campos da ética.

A noção de desenvolvimento como expansão de capacitações coloca ênfase na dinâmica das relações sociais a partir de um foco específico. Com essa percepção, é possível que muito da complexidade suprimida por conceitos que adjetivavam essa noção (desenvolvimento agrícola, desenvolvimento territorial, desenvolvimento sustentável) possam ser tratados na análise do processo de desenvolvimento, envolvendo, dessa forma, a expansão das capacitações por meio de novas oportunidades. Essa questão é essencial no sentido de determinar que tipo de medida social pode ser mais adequada na promoção desse processo (ou na eliminação da retenção de algumas capacitações, como por exemplo, na análise de situações de pobreza).

Essa noção permite compreender em que medida esses meios e fins podem ser distintos, procurando, assim, afastar-se definitivamente de uma normatização que valorize a homogeneidade, seja ela qual for. A questão é perceber que as 
relações sociais são diferentes e que agentes (e famílias) têm razões diferentes para valorizar determinados aspectos.

O rural é o lugar de convivência com aspectos naturais (sejam, ou não, construídos socialmente). Lugar esse em que as relações sociais estabelecidas são diferentes daquelas que norteiam as relações sociais no ambiente urbano (ambiente em que a produção é controlada unicamente pelo próprio homem). A vida no ambiente rural tem especificidades que tendem a ser valorizadas, uma vez que a modernidade tem cada vez mais apresentado claramente seus limites e incertezas que sugiram em sua grande maioria a partir da identificação e da construção social dos aglomerados urbanos. É entendido aqui como o lugar onde as complexas relações entre seus componentes não podem ser completamente condicionadas pela ação humana? .

Sendo assim, em termos metodológicos, a variável sugerida aqui como capaz de estabelecer o corte normativo sobre o que é rural e o que é urbano é a densidade demográfica. A relação entre a quantidade de pessoas que ocupa determinada área, ainda que possa ser questionada (assim como a construção de qualquer variável) é apontada aqui, não como a variável do "vazio", mas como a variável indicativa do não total condicionamento às ações humanas. É a variável "cheia" de um modo de vida que não é totalmente controlada pela racionalidade capitalista e que não controla completamente todas as relações de produção.

O exercício baseado na classificação territorial sugerida por Blume (2004) evidencia a importância de superar a noção de rural como aquilo que não é urbano. Em muitos estudos brasileiros sobre o ambiente rural, comumente se utilizam os dados disponíveis no IBGE, que indicam o rural como aquele que não é urbano. O urbano, por sua vez, corresponde a uma lei municipal que especifica o perímetro urbano. Sendo assim, os indicadores de urbanização podem não representar necessariamente um modo de vida, reconhecido empiricamente como urbano, por exemplo. No sentido de perceber com elementos que permitam reconhecer a dinâmica dos municípios por meio dos dados disponíveis, algumas propostas surgem o sentido de identificar o rural por meio de outros indicadores. Um desses estudos apresenta a abordagem Territorial Escalar Hierarquizada-TEH. Adaptada por Blume (2004), partindo de uma metodologia desenvolvida pela Organização para Cooperação e Desenvolvimento Econômico na Europa-OCDE, a TEH busca a classificação municipal entre rural e o urbano a partir de dois parâmetros de corte como referência: a densidade demográfica e o patamar populacional. Nesse sentido, segundo o autor:

\footnotetext{
7. Se estamos considerando o desenvolvimento com uma expansão das capacidades, que estão intimamente relacionadas às escolhas que os agentes sociais têm oportunidade de fazer, como estudá-lo num ambiente que conceitualmente não está completamente condicionado pela ação humana e que, portanto, por si só, poderia ser considerado como um "limitador" dessa própria condição de oportunidades? Aí é importante conhecer e ter claro que "controlar" o ambiente (essencialmente por meio de tecnologias de produção agrícola) não significa diretamente aumentar a oportunidade das pessoas que vivem nesse ambiente. A discussão é extensa. Por exemplo, a inserção de pacotes tecnológicos que reduzem a diversificação produtiva da unidade de produção que pode levar a uma dependência em relação a fornecedores. Esta situação estará, na realidade, reduzindo o conjunto capacitário e as oportunidades ao invés de aumentá-los. A liberdade é associada na abordagem aos fins - preservação de uma vida saudável, por exemplo, e não aos meios - acesso a bens e mercadorias.
} 
assim, para os municípios que apresentarem densidade demográfica menor a 80 hab./ km² serão classificados pela TEH como Municípios Rurais. Para os que apresentarem densidade demográfica maior ou igual a 80 hab./ km² ou um valor maior ou igual a 100.000 habitantes para população total, serão classificados como Municípios Urbanos" (BLUME, 2004. p.132).

Como exemplo da importância em termos de aproximação da percepção da realidade existente em cada município, pode-se citar o Município de Boa Vista do Sul. Pelo corte normativo do IBGE, esse município apresenta uma taxa de urbanização de $87 \%$. Isso indicaria que das cerca de 2.800 pessoas que vivem no município, 2.400 moram em áreas consideradas urbanas (FEE, 2004). Considerando a densidade demográfica do município $(29,98)$, pode-se imaginar que, não sendo um município com uma grande aglomeração populacional, sua paisagem predominante está relacionada a aspectos que não envolvem apenas um ciclo de vida ou produtivo que possa ser condicionada pelas pessoas ou famílias que moram nessa região, mesmo se considerarmos que esse município está economicamente relacionado com atividades agrícolas, que tem a transformação da paisagem e as decisões produtivas associadas ao trabalho e ao capital, tomadas pelas famílias. Não é possível controlar todo o processo produtivo, entre o tempo de produção e de trabalho há um tempo de não trabalho (humano) que envolve essa produção. Dessa forma, estaríamos reconsiderando a situação de diversos municípios em relação ao rural e distanciando-nos da noção do rural como aquilo que não é urbano.

Tentando analisar desenvolvimento rural, sob essas duas perspectivas do desenvolvimento, por meio da Abordagem das Capacitações e do rural, por meio da Abordagem TEH, a informação municipal parece ser a mais apropriada já que é o âmbito de gasto público, de administração e de participação política que mais diretamente afeta os agentes sociais e que são passíveis de sofrer uma influência direta quanto à reformulação de intitulamentos e à possibilidade de ampliação do conjunto capacitário. Nesse sentido, o desenvolvimento relaciona-se diretamente com a possibilidade de melhoria da qualidade de vida das pessoas e o rural, com uma relação com a paisagem.

Examinando as noções de desenvolvimento e de rural apresentadas, o desenvolvimento rural pode ser considerado como o aumento da possibilidade de escolha dos indivíduos que residem em ambientes constituídos por relações socioeconômicas, geográficas e culturais que evidenciam, por meio da paisagem, utilização e (ou) preservação de aspectos relacionados à Natureza, cuja reprodução não é inteiramente dependente e (ou) condicionada pela ação humana.

Essa percepção sobre o processo de desenvolvimento permite a integração do diversos fatores que estão sendo estudados a partir dos outros "desenvolvimentos rurais" sem, entretanto, limitar-se aos aspectos incorporados em cada uma delas. Com um objeto de análise bem construído e as possibilidades de operacionalização da abordagem seniana, é possível, a partir de um conceito claramente definido sobre o que é desenvolvimento rural, estudar toda a multiplicidade das relações que existem e que transformam o meio rural, tentando captar, nesse ambiente, as características e dinâmicas presentes, e não partindo de 
uma suposta noção do urbano, conhecer seus "vazios" e suas características "ausências".

Em relação à distinção entre meios e fins, pode-se considerar que a percepção seniana permitiria a identificação dos chamados intitulamentos, ou seja, aqueles elementos de infraestrutura que são capazes de promover o processo de desenvolvimento, reconhecido este como o aumento das oportunidades dos agentes de determinado território. Algumas variáveis, por exemplo, poderiam ser analisadas isoladamente ou em conjunto: acesso à renda; acesso a serviços de saúde e educação satisfatórios; preservação de direitos civis, aspectos culturais, de biodiversidade e ambientais; acesso a serviços de proteção contra riscos e desastres naturais.

Assim como as variáveis meio, o aumento efetivo das capacitações, por meio dos intitulamentos, o fim principal do processo de desenvolvimento poderia ser reconhecido por meio das seguintes variáveis, por exemplo: formação de expectativas; longevidade; participação social e política; identidade cultural; sensação de proteção; sentimento de integração social.

Em termos de funcionamentos, elementos que as pessoas escolhem realizar para levar a vida de acordo com aquilo que consideram uma boa qualidade de vida podem ser citados: diversidade produtiva; controle de doenças evitáveis; participação em atividades sociais, políticas e comunitárias; alimentar-se adequadamente; ler e escrever; conhecer direitos e deveres legais; identificar-se culturalmente com o local de moradia; viver num ambiente sem riscos ambientais evitáveis; garantir a reprodução da família no meio rural.

A partir do conceito de desenvolvimento rural associado a um processo de aumento das oportunidades disponíveis para as pessoas que convivem com aspectos naturais não totalmente controlados, é possível desenhar diversos estudos que, por sua vez, dados os problemas de pesquisa e seus objetivos, serão capazes de identificar de uma forma mais completa as relações sociais que permeiam esse ambiente.

\section{CONSIDERAÇÕES FINAIS}

Considerando o debate em torno da expressão desenvolvimento rural, o que se procurou neste artigo foi sugerir um conceito de desenvolvimento que fosse capaz de evidenciar os processos sociais que melhoram a qualidade de vida no ambiente rural. Defendido por alguns autores como um novo paradigma em relação ao desenvolvimento, que supera a noção de desenvolvimento associado ao crescimento econômico, esta abordagem procura "fugir" de avaliações unidirecionais sobre esse processo. O desenvolvimento (considerado como o aumento das capacitações) é sempre o fim normativo que se deseja do processo. Esse fim pode, dessa forma, ser analisado a partir da situação de cada território ou indivíduo. Isso significa assumir a posição de que superávits comerciais, por exemplo, se não auxiliam no aumento das possibilidades de escolhas das famílias brasileiras (assim como pode não ser um aspecto com razões para ser valorizado, nesse contexto), não devem ser avaliados como desenvolvimento per si. 
Ainda que se possa definir claramente de onde o pesquisador, que procura trabalhar com essa noção está falando, é preciso chamar a atenção em relação a algumas ressalvas que estão associadas a essa abordagem. Existe, ainda, discussão em torno de uma proposta adequada de metodologia (inclusive se é possível sua concepção ou não), da mesma forma, a abordagem seniana ainda é acusada de ser uma teoria "otimista" em relação à posição do agente social para a realização de mudanças (quando não se considera, por exemplo, a análise dos intitulamentos disponíveis).

Assim como o debate sobre desenvolvimento, a noção de rural vem cada vez mais necessitando de uma séria reflexão. O processo capitalista de produção evidentemente relegou, durante muito tempo, a análise do rural a um conceito associado àquilo que não é urbano. E essa noção teve como resultado, por exemplo, no Brasil, a uma estatística equivocada capaz de indicar um grau de urbanização de mais de $80 \%$. Entretanto, utilizamos invariavelmente, esses dados em diversos estudos sobre desenvolvimento rural (a própria noção de pobreza rural indicada na tabela apresentada na terceira seção deste texto poderia ser considerada uma ficção: se a pobreza é apenas avaliada pela renda e o rural é aquilo que não é urbano, qual a validade desse dado?). A alegação comum - e coerente é preciso deixar claro - é a de que esse é o dado que está disponível e que talvez permita identificar a ocorrência de diversos fenômenos sociais.

Por fim, pode-se evidenciar que estudar desenvolvimento rural não é, nem de longe, uma tarefa simples.. Talvez seja exatamente por isso que esse seja um campo tão impressionantemente envolvente e instigante de estudo - ainda que devamos assumir que, por vezes, bastante exaustivo e controverso. Atualmente, o essencial, quem sabe, nem seja que todos nós estejamos falando da mesma coisa, mas que cada um possa definir e explicar claramente sobre o que está falando quando utiliza a expressão desenvolvimento rural (e qualquer outro adjetivo que possa estar associado a essa expressão).

\section{REFERÊNCIAS}

ABRAMOVAY, Ricardo. Do setor ao território: funções e medidas da ruralidade no desenvolvimento contemporâneo. Rio de Janeiro: Texto para Discussão do IPEA $n^{\circ}$ $702,2000$.

AGUIAR, Afrânio C. Informação e atividades de desenvolvimento científico, tecnológico e industrial: tipologia proposta com base em análise funcional. Revista do Instituto Brasileiro de Informação em Ciência e Tecnologia. Brasília, 20(1):7-15, jan./jun. 1991.

BLUME, Roni. Território e ruralidade: a desmistificação do fim do rural. 2004. 182f. Dissertação (Mestrado em Desenvolvimento Rural) - Universidade Federal do Rio Grande do Sul, Porto Alegre, 2004.

CARNEIRO, M. J. Do rural e do urbano: uma nova terminologia para uma velha dicotomia ou a reemergência da ruralidade. Campinas: UNICAMP, 2001. 
CMMAD (Comissão Mundial sobre o Meio Ambiente e Desenvolvimento). Nosso Futuro Comum. Rio de Janeiro: Editora da FGV, 1991.

ELLIS, Frank; BIGS, Stephen. Evolving Themes in Rural Development 1950s-2000s. Development Policy Review. V. 19, $\mathrm{n}^{\circ}$. 4. Oxford:Blackwell Publishers. P. 437:448, 2001.

FEE (2004). População municipal e área dos municípios no Rio Grande do Sul. Informações disponíveis através de http://www.fee.tche.br em 10/out/2004.

GRAZIANO DA SILVA, José. O novo rural brasileiro. Campinas: UNICAMP, 1999.

LOPES, A. S. Desenvolvimento Regional. Fundação Galouste Gulbenkian: Lisboa, 2001.

MARSDEN, Terry; LOWE, Philip; WHATMORE, Sarah (edit.). Rural restructuring: global processes and their responses. London: David Fulton Publishers, 1990.

NAVARRO, Zander. Desenvolvimento rural no Brasil: os limites do passado e os caminhos do futuro. Estudos Avançados. v. 16, n 44. São Paulo: USP. 2002.

Do 'mundo da roça' ao mercado: mudanças recentes e o desenvolvimento agrário no Sul do Brasil (Políticas públicas e desenvolvimento rural). Brasília: Ministérios do Desenvolvimento Agrário. Mimeo, 2002

NUSSBAUM, Matha. Woman and human development: the capability approach. Cambridge: Cambridge University Press, 2000.

SACHS, Wolfgang. Anatomia Política do Desenvolvimento Sustentável. Democracia Viva. No 1. Novembro. P.11-23, 1997.

SARACENO, Elena. Recents Trends in Rural Development. Journal of Rural Studies. V. 10, no 4. P. 321-330, 1995.

SCHEJTMAN, Alexander; BERGDEGUÉ, Julio A. Desarrollo Territorial Rural. Santiago. Mimeo, 2003.

SANTOS, M. O retorno do território. In: Santos, M.; SOUZA, M. A. A. de; SILVEIRA, M. L.; (orgs.). Território: globalização e fragmentação. São Paulo: HUCITEC, Anpur: 1994.

SEN, Amartya. Desigualdade reexaminada. Rio de Janeiro: Record, 2001.

. Desenvolvimento como liberdade. São Paulo: Companhia das Letras, 2000.

O desenvolvimento como expansão das capacitações. Lua Nova Revista de Cultura e Política. №. 28. São Paulo: CEDEC, 1993. 
VEIGA, José El. A face territorial do desenvolvimento. Mimeo. S/D.

WORLD BANK. World Development Report 2005: a Better Investment Climate for Everyone. Washington: Oxford University Press. Disponível através de http//: www.worldbank.org em 18 de dezembro de 2004.

YUNUS, Muhammad. O banqueiro dos pobres. Ed. Ática: São Paulo, 2000.

Submetido em 04/12/2013

Aprovado em 24/06/2015

\section{Sobre a autora \\ Daniela Dias Kühn}

Economista. Mestre e Doutora em Desenvolvimento Rural pelo Programa de Pós Graduação em Desenvolvimento Rural da Universidade Federal do Rio Grande do Sul (PGDR/UFRGS). Professora Adjunta do Departamento de Ciências Econômicas da Universidade Federal de Santa Maria (UFSM). Professora do Programa de Pós Graduação em Economia e Desenvolvimento (PPGE\&D/UFSM).

Endereço: Rua Dalila Tonetto Behr, 592. 97110-807 - Santa Maria - RS - Brasil.

E-mail: daniela.kuhn@ufsm.br. 